\title{
The Potential of the Internet of Things in Knowledge Management System
}

\author{
Artur Rot \\ Wroclaw University of Economics \\ ul. Komandorska 118/120 \\ 53-345 Wroclaw, Poland \\ Email: artur.rot@ue.wroc.pl
}

\author{
Malgorzata Sobinska \\ Wroclaw University of Economics \\ ul. Komandorska 118/120 \\ 53-345 Wroclaw, Poland \\ Email: malgorzata.sobinska@ue.wroc.pl
}

\begin{abstract}
Along with the increasing globalization and development of information and communication technology, business models are changing, and thus the need for innovative knowledge management is growing. Current knowledge management systems very often are not used optimally/effectively for decision-making because of the lack of real-time data. This article draws attention to the current trend in the area of organization management and IT management related to the emergence and growing popularity of the Internet of Things. The authors try to assess the potential of IoT in the context of improving knowledge processes (locating, acquiring, using, sharing and disseminating as well as preserving / coding / archiving / collecting), especially acquiring and sharing data and determining IoT impact on knowledge management and learning of the organization. The possible positive effects of implementing IoT in enterprises of various types, as well as threats and challenges that must be met by organizations that care about increasing their competitive position using IoT will be presented.
\end{abstract}

\section{INTRODUCTION}

$\mathrm{S}$ uccess of organisations is, to a large extent, a function of their investment in knowledge and their ability to accumulate and create knowledge. Management of organisations in the 21 st century is inextricably linked with creative application of knowledge processes management techniques and the organisational capacity to adapt to changing conditions, based on the rapid development of modern technologies. This approach offers potential of largely improving the decision-making effectiveness, operating capacity, flexibility and employee involvement in organisations.

Organisational processes are the basis for making informed decisions based on knowledge. The development and utilisation of intelligent solutions - such as those involving Big Data processing and the Internet of Things seems to place strong emphasis on open, systemic approach. For instance, the introduction of fully digitalised services paves the way for the design of new interfaces between service providers and end users.

Proper selection and continuous improvement of ICTbased business models seems particularly important for those organisations which place emphasis on cognisant application of knowledge management techniques and on the practical implementation of the concept of "the learning organisation" where learning processes are perceived as fundamental for building and maintaining the competitive advantage through continuous advancement and exploration of new paths for organisational development. Organisations of this type are usually more open and receptive to signals from their environment and are more capable of forging those signals into tangible benefits: learning, improvement, and change. As aptly noted by Stańczyk-Hugiet, the most fundamental process in a learning organisation is the one involving transformation of information into knowledge resources which then are used as basis for building a unique selling position on the market [6, p. 136].

Knowledge has become the most important resource of any organisation and a key to its continued growth. Similarly, Kaivo-oja et al. argue that intelligent organisations are those that focus not so much on knowledge production but rather on proper integration of knowledge. In this way, knowledge integration has been elevated to the rank of a key component of a modern management system [11].

The Internet of Things (IoT), defined as the sum of intelligent appliances capable of responding to environmental stimuli as well as storing and processing of digital information and relaying it to other agents (or users) via Internet protocols, seems to offer best potential for supporting the aforementioned task of turning information into knowledge. This context needs careful research, as the subject of IoT and its potential impact on knowledge management systems is, thus far, inadequately represented in professional literature.

This paper places the particular emphasis on capabilities offered by Internet of Things in the context of process optimisation in tasks involving accumulation, transfer, and filtering of data to be used in decision-making scenarios across various operating segments of a contemporary company. 


\section{KNOWLEDGE MANAGEMENT - IT INSTRUMENTS IN SUPPORT OF KM}

From a managerial perspective, companies are in urgent need of developing and improving their capacity to operate under the constantly changing, non-linear and largely unforeseeable conditions brought about by the challenges of modern digital evolution. In view of the above, effective knowledge management should focus, most of all, on the following: improving the time of response to environmental stimuli through better access to knowledge and applications; creating and maintaining potential for company growth and development; improving the company value and/or profitability; improving company products and services, stimulating the production of knowledge, reducing the cost of operation, ensuring constant improvement of quality and effectiveness. However, as observed by Uden and He, the traditional knowledge management systems are burdened with certain limitations.

The authors postulate that the next generation of knowledge management systems in the age of IoT should offer the following capabilities [7]:

- Creation of personalised experience and tracking of its various sources;

- Transfer and reorganisation of data from various sources;

- Data optimisation and pre-processing of data for various purposes and applications;

- Provision of on-demand and real-time updates of data used in decision-making contexts;

- Collection of machine data and user activity data for process improvement purposes;

- Ensuring the fluidity and interoperability of the various components of the knowledge management system.

It seems valid to assume that the informative potential of the Internet with respect to the management of large data repositories and knowledge discovery is growing at a rapid pace, with the advance of such technologies as the IoT, intelligent computing, machine learning, big data, cloud computing and sensor technologies. Those and other modern IT solutions may largely improve the effectiveness of data management and knowledge discovery processes in a modern organisation. One of the prime objectives of knowledge management is the effective filtering of data originated from unreliable sources.

At present, the use of IoT in modern knowledge management systems offers potential for not only real-time updates and synthetic evaluation of data from various sources, but also the capacity for knowledge discovery. With the growing popularity of the Internet as a medium of communication, modern companies are more inclined to redefine their existing business models, i.e. the company prime objectives and approaches to value creation. By basing their business models on the IoT, organisations may benefit from the wealth of new channels and means for value exchange. At the same time, the IoT may be perceived as an innovation, since it involves a creative use of the existing services and protocols for the development of new, more responsive and dynamic products and services. When viewed from the context of an innovation, the IoT represents a broad spectrum of intelligent technologies capable of communicating directly with the user or with other machines and agents to offer a brand new level of interaction or information retrieval in any environment populated by such objects [12].

\section{NEW CAPABILITIES FOR THE RETRIEVAL OF INFORMATION AND KNOWLEDGE FOR DECISION-MAKING PURPOSES}

Organisations employ information and knowledge both for the improvement of their decision-making processes and for the legitimisation of decisions (including those issued on the basis of unreliable information). In addition, it seems valid to assume that modern organisations retrieve and store much more information than needed for their decisionmaking purposes, and still call for more. The overabundant supply of information may come as a result of various forces and trends at play. For instance, organisations tend to underestimate the cost of information retrieval in proportion to the benefits offered. Usually, decisions made with respect to information are delegated to the authority of units other than those directly involved in its retrieval. By maintaining such clear separation between information use and information retrieval/storage, decision makers are able to initiate information retrieval procedures they deem of potential value for them, but without taking heed of the real cost-benefit ratio as perceived from the viewpoint of the organisation as a whole. The rationality of information oversupply can also be viewed in the context of strategic value of information, particularly when such information is employed to enforce certain response rather than serve as basis for rational decisions. In organisational settings, information is rarely of neutral character. Most of the information feed is prone to misinterpretation. From the viewpoint of decision makers, it is better to have access to information deemed unproductive (for decision-making purposes) than to bear the risk of missing information that may ultimately prove valuable [11].

Both the Internet of Things and cloud computing offer potential to simplify the identification of requirements to be addressed by knowledge management systems and to improve their effectiveness by providing real-time access to data/information ("just in time" and "right on point").

The Internet of Things is also perceived as another important factor to affect the transaction processes, most specifically: the methods for identifying and satisfying customer needs and requirements. Based on different recent reports and surveys, the number of objects connected to the Internet, including smartphones, is already in excess of the total Earth population and, according to the Gartner report, will reach 26 billion wireless devices by the end of 2020 [14]. 


\section{THE INTERNET OF THINGS - SELECTED AREAS OF APPLICATION}

The Internet of Things can be defined as the sum of intelligent appliances capable of responding to environmental stimuli as well as storing and processing of digital information and relaying it to other agents (or users) via Internet protocols [15]. It represents a networking structure of independent devices designed to enable and facilitate decentralised communication between each and every node. The concept is based on continued technological advancement and utilisation of the existing structures of communication to serve as a medium for unrestrained exchange and sharing of information between numerous devices, appliances and sensors.

It must be noted at this point that the Internet of Things can also be perceived as the latest fashion and may be prone to various interpretations. The term itself may relate to any clearly identifiable object capable of - directly or indirectly - storing and processing data. The number of such objects grows exponentially, along with the spectrum of their potential applications. The IoT is closely associated with the Big Data concept, since the effective provision and processing of large amounts of data is deemed to be the core benefit offered by IoT solutions [13].

There are many potential areas of IoT application and the solution may be adopted with success in many aspects of modern life. According to the Gartner report, the IoT will soon generate revenue in excess of USD $300 \mathrm{bn}$, mostly in services [14]. Similarly, the McKinsey\&Company [16] report suggests that the IoT may soon produce global economic profit between USD 2.7 and 6.2 trillion by the year 2025. IoT will find its use in many areas of economic activity and in many sectors, including energy, production, logistics, health care, IT. With further rapid expansion (which seems fairly inevitable), the IoT will manifest its potential in other areas, such as intelligent construction, intelligent vehicles and cities, and in industrial automation (often referred to as Industry 4.0). Table I presents one of the most popular categorisations of potential IoT applications, as postulated by Beecham Research [17].

There are certain areas of the socio-economic life which offer particular benefits from the use of IoT solutions, in terms of value creation. According to the report by McKinsey\&Company consulting agency, nine such areas can be distinguished [18]: human, home, retail environments, office, factories, worksites (e.g. oil rigs), vehicles, cities, and outside areas (i.e. spaces between urbanised areas). The Internet of Things will find many uses in various segments of business and services sector.

At the same time, the potential economic impact of the IoT will vary from segment to segment. The McKinsey forecast suggests that, by the year 2025, the highest revenues will be observed in production (1.2-3.7 trillion USD), and the lowest - in office environments (70-150 billion USD) [18].
TABLE I.

THE INTERNET OF THINGS - AREAS OF APPLICATION

\begin{tabular}{|c|c|c|}
\hline No. & Sector & Examples of applications \\
\hline 1 & Construction & $\begin{array}{l}\text { Automated heating, ventilation, air- } \\
\text { conditioning, access control, lighting, } \\
\text { security systems, etc. }\end{array}$ \\
\hline 2 & Energy & $\begin{array}{l}\text { Resource extraction and mining, } \\
\text { exploration of alternative (renewable) } \\
\text { energy sources, electric generators. }\end{array}$ \\
\hline 3 & $\begin{array}{l}\text { Household and } \\
\text { consumer goods }\end{array}$ & $\begin{array}{l}\text { Household security (alarms, monitoring } \\
\text { of seniors and children), control and } \\
\text { regulation of devices (including energy } \\
\text { supply and lighting), home } \\
\text { entertainment systems. }\end{array}$ \\
\hline 4 & $\begin{array}{l}\text { Health care and } \\
\text { natural sciences }\end{array}$ & $\begin{array}{l}\text { Telemedicine, remote monitoring of } \\
\text { patients and seniors (e.g. patients with } \\
\text { cardiac pacemakers), research and } \\
\text { development of drugs and medical } \\
\text { equipment, }\end{array}$ \\
\hline 5 & Industry/production & $\begin{array}{l}\text { Monitoring and tracking of assets, } \\
\text { machinery and industrial products, } \\
\text { location analyses for a wide range of } \\
\text { industrial and factory processes. }\end{array}$ \\
\hline 6 & Transport & $\begin{array}{l}\text { Fleet management (navigation systems, } \\
\text { distribution management), passenger } \\
\text { information systems, automated toll/fee } \\
\text { collection systems (motorways, } \\
\text { parking). }\end{array}$ \\
\hline 7 & Retail & $\begin{array}{l}\text { Supply chain management, } \\
\text { product/client information } \\
\text { management, stock management, } \\
\text { vending machines (foods, beverages), } \\
\text { parking meters, information display } \\
\text { systems (billboards, digital displays). }\end{array}$ \\
\hline 8 & Public safety & $\begin{array}{l}\text { Monitoring of environmental hazards, } \\
\text { meteorological and climate } \\
\text { information, tracking of } \\
\text { persons/animals/packages, military } \\
\text { security. }\end{array}$ \\
\hline 9 & IT sector & $\begin{array}{l}\text { Office appliances, mobile } \\
\text { communication infrastructure, data } \\
\text { relay centres (automated energy and } \\
\text { air-conditioning relay systems), e- } \\
\text { commerce, etc. }\end{array}$ \\
\hline
\end{tabular}

To sum up, it may be stated that the Internet of Things offers potential support in nearly all areas of human life and has already become an indispensable element of modern existence in an information society.

Lastly, by connecting many of their home or office devices to the Internet, individual consumers and organisations may receive additional benefits, such as energy savings or new business opportunities.

\section{THE ORGANISATIONAL POTENTIAL OF THE IOT}

With the rapid changes observed in modern economic environment, companies face more and more fierce competition and are expected to meet the mounting expectations of their customers. To oppose this trend, modern companies place great emphasis on improving the effectiveness of their day-to-day operations. For this purpose, company management needs constant and real-time 
access to reliable and verifiable information on the present condition of their enterprise or unit, as a prerequisite for making accurate and informed business decisions. Lambert believes that the world at present is witness to a global technological revolution, and that the Internet of Things is only a part of a large-scale phenomenon.

It is true that the IoT has become an indispensable element of most any modern technological solution employed in business. By making good use of constant connectivity between integrated devices, human resources and data, companies will be better equipped to analyse and respond to the changing needs of their customers and effect prompt changes in their supply chains or innovative implementations. The IoT may also improve the quality of life (for customers, consumers) by offering remote and automated fee collection, monitoring of health, etc. In addition, the IoT may soon dominate such areas of everyday life as waste management, energy management or traffic control [20].

Data presented by T-Mobile suggests that investment in the IoT brings tangible returns in terms of employee effectiveness, utilisation of material resources, cost of operation, monitoring effectiveness, employee safety, integrated supply chain management, and creation of value from new products and services [21].

As suggested by the authors of the IDC report, companies and consumers as well as the whole ecosystem of IoT solutions suppliers may soon see many benefits from the continued advancement of the associated technologies. These may include the following [22]:

- New business models. Faced with a highly competitive markets, both sellers and enterprises constantly seek new ways of conducting their business and new methods for effective creation of customer value. Companies operating within the B2B model may utilise IoT solutions to automate some of their business processes to gain fast access to the market and to better respond to changes in customer needs.

- Mission-critical processes and products. IoT solutions may help companies gain more data on own processes and products. In some cases, such supplementary data may provide crucial and valuable information of corporate character, to allow for operational changes and real-time decision-making. In other scenarios, such supplementary data may be used to support curative and diagnostic decisions in patient care or improve the accuracy of shopping suggestions and offers designed for specific customer segments.

- Diversification of revenues. The Internet of Things may offer potential for innovations, particularly to sellers and service providers, which may result in new products and services.

- For some types of enterprises, IoT may prove a valuable source of supplementary income, attached to the servicing of products in circulation. For instance, providers of vending machines may offer a range of associated services, such as the automated monitoring and resupply of stock.

- Global players. By making good use of the IoT functionality, organisations may gain improved access to their business structures and units (including remote locations), with potential to monitor, manage, and track the operation of each independent node. For some enterprises, such a transition may prove of particular value, by offering remote resource and product management capabilities.

- Efficient intelligent operations. The Internet of Things will greatly affect the way companies make their decisions, as optimisation and productivity improvements may now be managed in real time. With instantaneous access to relevant information on independent nodes based on the use of own or customer resources - and with potential to promptly address any problem revealed by the data feed, organisations may find reasons to redesign their business processes to improve their long-term effectiveness and productivity.

- Increased expectations. With more consumers, organisations and institutions being aware of the life quality improvements and savings offered by products and services on the market, their expectations towards new products and services will naturally rise. This will stimulate further increase of market competition between various actors and suppliers involved in the IoT segment (ecosystem).

It goes without saying that the utilisation of the full potential offered by the IoT solutions will not be easy, since organisations need new sets of skills and technological tools to ensure proper implementation and protection of large systems responsible for the servicing of hundreds of thousands, if not millions, of individual, spatially dispersed and independent nodes [23].

\section{THE BENEFITS OF INTERNET OF THINGS IN SELECTED AREAS OF KNOWLEDGE MANAGEMENT}

The Internet of Things also brings a number of benefits in the area of the knowledge management system. The most important of them, combined with potential risk areas, are presented in the Table II.

Knowledge management today has also the opportunity and the capability to synthesise data from diverse sources and to create new knowledge. Because of the IoT, businesses today are forced to rethink their goals. With the IoT, products can be tracked anytime, making it possible to respond to customer behaviour. It is also now possible for products to connect with other products, leading to new analytics and new services for more effective forecasting, process optimisation and customer service experiences [24] [28]. 
TABLE II .

THE MAIN BENEFITS AND RISKS OF IMPLEMENTATION OF INTERNET OF THINGS IN SELECTED AREAS OF KNOWLEDGE MANAGEMENT

\begin{tabular}{|c|c|c|}
\hline $\begin{array}{l}\text { Areas/objectives of } \\
\text { knowledge } \\
\text { management }\end{array}$ & The potential of Internet of Things & The risk associated with the IoT implementation \\
\hline $\begin{array}{l}\text { Strategy/development of } \\
\text { knowledge and } \\
\text { competence resources }\end{array}$ & $\begin{array}{l}\text { Access to external expertise, the latest technology; } \\
\text { providing tools to enable access to organizational and } \\
\text { technological knowledge; providing tools for support of the } \\
\text { transfer and sharing of knowledge. }\end{array}$ & $\begin{array}{l}\text { Need of better control over the IoT environment; } \\
\text { Dependence on the suppliers of IoT. }\end{array}$ \\
\hline $\begin{array}{l}\text { Human resources } \\
\text { management/ } \\
\text { development of } \\
\text { intellectual capital }\end{array}$ & $\begin{array}{l}\text { Developing new skills and competences in the field of IT; } \\
\text { Improved cooperation and transfer of knowledge between } \\
\text { organizations. }\end{array}$ & $\begin{array}{l}\text { Possible loss of intellectual capital in case of the dismissal } \\
\text { of IT staff as a result of the adaptation of IoT solutions; } \\
\text { The need to improve knowledge and to develop new skills } \\
\text { to use the new technology (IoT) }\end{array}$ \\
\hline Process management & $\begin{array}{l}\text { Supporting innovation; } \\
\text { Reducing the time of process implementation. }\end{array}$ & \\
\hline $\begin{array}{l}\text { Marketing/business } \\
\text { intelligence/innovation }\end{array}$ & $\begin{array}{l}\text { Possibly unlimited access to internal and external data. } \\
\text { Ensuring the possibility of direct integration of external } \\
\text { entities with the company; } \\
\text { Supporting market-driven innovation (for } \\
\text { products/services). }\end{array}$ & $\begin{array}{l}\text { The possibility of losing competitive advantage by } \\
\text { acquiring strategic information or sensitive data by the } \\
\text { competitors. }\end{array}$ \\
\hline $\begin{array}{l}\text { Information } \\
\text { technology/Information } \\
\text { security management }\end{array}$ & $\begin{array}{l}\text { Improved use of IT resources; } \\
\text { Possibility of collecting data from diverse products, } \\
\text { company assets or the operating environment; } \\
\text { Possibility of the transmission of real-time data from } \\
\text { wireless network }\end{array}$ & $\begin{array}{l}\text { Loss of control over the IT environment; } \\
\text { System failures; } \\
\text { Services unfit for the actual needs of the organization; } \\
\text { The possible decrease in safety; } \\
\text { The possibility of loss and/or unauthorized use of sensitive } \\
\text { data. }\end{array}$ \\
\hline
\end{tabular}

Sensors and embedded technology now enable the transmission of real-time data from wireless networks which will lead to the co-creation of new real-time knowledge among customers and vendors. Companies which use the IoT can gather data about how their products behave and interact, and can then use it to understand and predict future behaviours [7].

Companies can also use the data collected from sensors to change the way that they design, upgrade and maintain devices in the field. The result is not merely greater efficiency, but entirely new functionality and levels of service. Real-time monitoring and analysis of physical assets allow companies to understand and act on a variety of realtime insights. The real-time data can be accessible by all the stakeholders, thereby facilitating knowledge sharing. Organisations using KM have the ability to interpret the realtime data and convert them into real-time knowledge for competitive advantage [7].

IoT can also help KM to capture data to be used in organisations. The world of connected devices today presents the opportunity for organisations to create new product experiences.

The increasing use of internet-enabled devices with sensors provides more opportunities both to improve the way services are delivered and to harness those data to gain faster insights into whether interventions are working. Manufacturers are using data obtained from sensors embedded in products to create innovative after-sales service offerings such as proactive maintenance to avoid failures in new products [25] [26].
The data also enable companies to design better products in the future. KM today has the opportunity and the capability to synthesise data from diverse sources and arrive at new knowledge. The benefits of IoT for KM can be summarised as follows [7] [27]:

- IoT enables a user to collect data from diverse products, company assets or the operating environment. It allows for the generation of better information and analysis, which can significantly enhance decision-making.

- When products are embedded with sensors, companies can track the movements of these products and can monitor interactions with them. Businesses can take advantage of customers' behavioural data to make appropriate decisions.

- Data from large number of sensors, deployed in infrastructure (such as roads and buildings), can give decision makers a heightened awareness of real-time events, particularly when the sensors are used with advanced display or visualization technologies [27].

- The IoT can support longer-range and more complex human planning and decision-making.

- The IoT can raise productivity, because the IoT can help systems adjust automatically to complex situations, which can make a number of human interventions unnecessary.

- The IoT enables rapid, real-time sensing of unpredictable conditions and instantaneous responses guided by automated systems. 


\section{CONCLUSION}

New, breakthrough technologies, in particular the Internet of Things, change the way knowledge is managed in organizations, forcing the implementation of innovative knowledge management systems and an open approach to supporting knowledge flows. Bearing in mind their importance already today, IoT and Big Data most definitely are key factors affecting societal development in the future. Private and public organizations have begun to gain critical insights from the Big Data and ubiquitous technology through various management systems. Basically, the issue at stake here is the fact that it is not just the question how to manage and control the technological possibilities. The development also concern leadership functions. Namely, taking seriously Internet of Things and ubiquitous technology may lead towards the revolution of digitalization which effects on knowledge management processes in organizations.

The authors intend to conduct further, more detailed research on the impact of IoT on knowledge management processes in organizations, such as: locating knowledge, acquiring knowledge, developing knowledge, sharing, using and protecting knowledge.

\section{REFERENCES}

[1] A. Rot, M. Sobińska M., "Knowledge management in the cloud computing model - challenges, opportunities and risks", in Position Papers of the 2017 Federated Conference on Computer Science and Information Systems, M. Ganzha, L. Maciaszek, M. Paprzycki (eds.), Annals of Computer Science and Information Systems, vol. 12, 2017, Polskie Wydawnictwo Informatyczne, Warsaw, 2017, pp. 177-181.

[2] M. Dolińska, Innovations in knowledge based economy, (In Polish) Warsaw, Polskie Wydawnictwo Ekonomiczne, 2010.

[3] E. Stańczyk-Hugiet, Strategic context of knowledge management, (In Polish), Wroclaw University of Economics Publishing House, Wroclaw, 2007.

[4] L. Uden, W. He, "How the Internet of Things can help knowledge management: a case study from the automotive domain ", Journal of Knowledge Management, Vol. 21 Issue: 1, 2017, https://www.emeraldinsight.com/doi/pdfplus/10.1108/JKM-07-20150291, pp.57-70.

[5] U. Ganesh, Internet of things: Impact on learning and knowledge management, Financial Express 22-nd of December 2014, https://www.financialexpress.com/industry/technology/internet-ofthings-impact-on-learning-and-knowledge-management/21816/

[6] G. Santoro, D. Vrontis, A. Thrassou, L. Dezi , "The Internet of Things: Building a knowledge management system for open innovation and knowledge management capacity", Technological Forecasting and Social Change, Available online 16 March 2017, Elsevier, 2017, https://www.sciencedirect.com/science/article/pii/S00 40162517302846?via\%3Dihub

[7] M. Krysiński, "The Internet of Things - innovative tool for companies”, (In Polish) Ekonomiczne Problemy Ustug no. 122, University of Szczecin, Szczecin 2016, http://www.wzieu.pl/zn/epu/122/epu_122.pdf, pp. 281-290.

[8] J. Kaivo-oja, P. Virtanen, H. Jalonen, J. Stenvall, "The Effects of the Internet of Things and Big Data to Organizations and Their Knowledge Management Practices", Conference Paper in Lecture Notes in Business Information Processing, August 2015.
[9] A. Murray, A. Papa, B. Cuozzo, G. Russo, "Evaluating the innovation of the Internet of Things: Empirical evidence from the intellectual capital assessment”, Business Process Management Journal, Vol. 22 Issue: 2/2016, Emerald Insight, https://www.emeraldinsight.com/doi/abs/10.1108/BPMJ-05-20150077, pp. 341-356.

[10] J. Holler, V. Tsiatsis, From Machine-to-Machine to the Internet of Things: Introduction to a New Age of Intelligence, Elsevier, 2014.

[11] P. Middleton, P. Kjeldsen, J. Tully, Forecast: The Internet of Things, Worldwide 2013, Gartner, November 2013, www.gartner.com/doc/2625419/forecast-internet-things-worldwide-.

[12] W. Nowakowski, "Closer to the cloud, computational services in the fog” (In Polish), Elektronika - konstrukcje, technologie, zastosowania $\mathrm{nr}$ 5/2015, Instytut Maszyn Matematycznych, Warsaw 2015, http://www.imm.org.pl/imm/plik/pliki-do-pobrania-elektronika52015 nn358.pdf

[13] McKinsey\&Company, The Internet Of Things: Mapping The Value Beyond The Hype, McKinsey Global Institute, 2015 http:/www.mckinsey.com/business-functions/digital-mckinsey/ourinsights/the-internet-of-things-the-value-of-digitizing-the-physicalworld.

[14] Beecham Research, IoT Sector Map, 2016, http://www.beechamresearch.com/article.aspx?id=4.

[15] H. Bauer, M. Patel, J. Veira, The Internet of Things: Sizing up the opportunity, http://www.mckinsey.com/industries/high-tech/ourinsights/the-internet-of-things-sizing-up-the-opportunity, McKinsey\&Company, 2014.

[16] M Van Rijmenam M., Three Major Challenges for the Internet of Things, http://www.datafloq.com/read/three-major-challengesinternet-of-things/83

[17] EY, Insights on governance, risk and compliance: Cybersecurity and the Internet of Things, Ernst \& Young 2015, www.ey.com/Publication/vwLUAssets/EY-cybersecurity-and-theinternet-of-things/\$FILE/EY-cybersecurity-and-the-internet-ofthings.pdf

[18] D. Niyato, Economics of Internet of Things (IoT): An Information Market Approach, Computer Science, 2012.

[19] D. Lund, C. MacGillivray, V. Turner, M. Morales, Worldwide and Regional Internet of Things (IoT) 2014-2020 Forecast: A Virtuous Circle of Proven Value and Demand, Worldwide Semiannual Internet of Things Spending Guide IDC, 2014, https://www.business.att.com/content/article/IoT-worldwide_regional 2014-2020 -forecast.pdf.

[20] A. Rot, B. Blaicke B., "The Internet of Things Security. Selected threats and countermeasures. Manufacturing systems case study" [In Polish], Management, Czestochowa Technical University, no. 26, 2017, pp. 188-198.

[21] G. Hui, How the Internet of Things Changes Business Models, Harvard Business Review, 29 July 2014, https://hbr.org/2014/07/howthe-internet-of-things-changes-business-models

[22] L. Xu, W. He, S. Li, Internet of Things in industries: a survey, IEEE Transactions on Industrial Informatics, Vol. 10 No. 4, 2014, pp. 22332243.

[23] W. He, L. Xu, "A state-of-the-art survey of cloud manufacturing”, International Journal of Computer Integrated Manufacturing, Vol. 28 No. 3, 2015, pp. 239-250.

[24] Z. Bi, G. Wang, L.D. Xu, "A visualization platform for Internet of Things in manufacturing applications", Internet Research, Vol. 26 No. 2, 2016, pp. 377-401.

[25] K. H. Badimo, The Increasing Importance of Knowledge Management in the Digital World through the Internet of Things, https://www.linkedin.com/pulse/increasing-importance-knowledgemanagement-digital-world-kgabo-badimo/

[26] A. Rot, M. Sobińska, "IT security threats in cloud computing sourcing model", Proceedings of the 2013 Federated Conference on Computer Science and Information Systems, M. Ganzha, L. Maciaszek, M. Paprzycki (eds.), 2013, IEEE, pp. 1141-1144. 